\title{
Redes de colaboração e intersetorialidade nas creches públicas do estado de Sáo Paulo
}

\author{
Claudia Maria Simóes Martinez ${ }^{\mathrm{a}}$, Anne Marie Germaine Fontaine ${ }^{\mathrm{b}}$, \\ Jair Ferreira Licio dos Santos ${ }^{\mathrm{c}}$, Bruna Pereira Ricci Marini ${ }^{a}$, Mariana Gurian Manzini ${ }^{\mathrm{a}}$ \\ ${ }^{a}$ Departamento de Terapia Ocupacional, Universidade Federal de São Carlos - UFSCar, São Carlos, SP, Brasil.

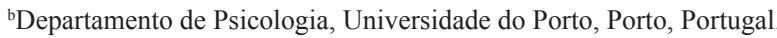

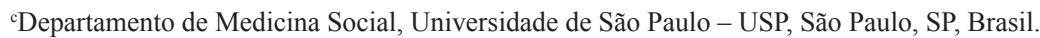

\begin{abstract}
Resumo: Introdução: A literatura indica impactos positivos no desenvolvimento infantil de crianças que frequentam creches quando, neste contexto, há boas práticas. Acredita-se que um conjunto de ações, em rede, coordenadas pelos gestores, pode impactar positivamente o desenvolvimento integral da criança. Objetivo: Embora a literatura aponte os campos de conhecimento "saúde, educação e o social" como as redes de colaboração das creches, o objetivo desta pesquisa foi identificar redes de colaboração no contexto de creches públicas do Estado de São Paulo. Método: A metodologia contemplou etapas para efetivação dos procedimentos éticos e definição do plano amostral, que resultou em 32 creches dos municípios do Estado de São Paulo. Os dados foram coletados por meio de entrevistas feitas com os dirigentes das creches que buscaram identificar os pontos da rede, a partir de situações presentes em sua prática cotidiana. Resultados: Os resultados apontaram para a presença de 75 pontos de rede de colaboração nos 32 municípios com distintas parcerias de serviços, ora contando com redes mais extensas, ora mais curtas. Confirmou-se a forte presença da intersetorialidade advinda dos campos da educação, da saúde e do social. Além destes, equipamentos municipais para ações de infraestrutura foram também identificados, bem como a presença de diversos programas governamentais oriundos da esfera federal. Conclusão: A dimensão do desenvolvimento infantil está presente de forma intensa na esfera da educação e da saúde. Os dados foram discutidos na perspectiva do apoio aos dirigentes para a resolutividade dos problemas, considerando-se o potencial das ações preventivas na primeira infância.
\end{abstract}

Palavras-chave: Desenvolvimento Integral da Criança, Intersetorialidade, Creches.

\section{Collaboration networks and intersectoriality in public daycares of Sáo Paulo state}

\begin{abstract}
Introduction: The literature indicates positive impacts on child development for those children attending day care centers, when this context includes good practices. It is believed that a set of actions, networking, coordinated by managers can positively to impact the children development. Objective: Although the literature indicate the fields of knowledge "health, education and social" as the daycare collaborative networks, this study evaluated are the points that allow connections in these networks today, and the possible existence of other networks describing their characteristics. Method: The methodology included ethical procedures and definition of the sampling plan, which resulted in 32 daycare schools in the municipalities of São Paulo. Data were collected through interviews with the daycares directors seeking to identify the network points, from situations present in their daily practice. Results: The results showed the presence of 75 points of the cooperation network in 32 municipalities with different service partnerships, sometimes with more extensive networks, or shorter. We highlight the strong presence of
\end{abstract}

Autor para correspondência: Claudia Maria Simões Martinez, Departamento de Terapia Ocupacional, Universidade Federal de São Carlos, Rodovia Washington Luiz, Km 235, CP 676, CEP 13565-905, São Carlos, SP, Brasil, e-mail: claudia@ufscar.br Recebido em Jul. 16, 2015; $1^{\text {a }}$ Revisão em Out. 24, 2015; Aceito em Nov. 20, 2015. 
intersectorality arising from the fields of education, health and social. Municipal equipment for infrastructure actions were identified, as well as the presence of various government programs from the federal level. Conclusion: The scale of child development is present in an intense way in the sphere of education and health. The data are discussed from the perspective of supporting leaders for solving the problems considering the potential of preventive action in early childhood.

Keywords: Development of Children, Intersectoriality, Day Care.

\section{Introdução}

O presente artigo deriva dos dados da pesquisa Programas de atenção ao desenvolvimento infantil em creches: identificação e difusão das boas práticas no Estado de Sáo Paulo, financiada pela FAPESP e pela Fundação Maria Cecília Vidigal. Foi executada na Universidade Federal de São Carlos por meio do Departamento de Terapia Ocupacional e do Laboratório de Atividades e Desenvolvimento. Resulta da cooperação entre docentes do Departamento de Terapia Ocupacional, do Departamento da Ciência da Informação e do Departamento de Psicologia da UFSCar, e inclui colaboradores de outras duas instituiçôes, a Universidade de São Paulo e a Universidade do Porto, Portugal.

O objetivo principal da pesquisa consiste em identificar, analisar e difundir boas práticas de promoção ao desenvolvimento de crianças entre zero e três anos em creches do Estado de Sáo Paulo. Acredita-se que os avanços das tecnologias de informação e de comunicação, tão bem desenvolvidas e disponíveis no início do século XXI, podem se constituir nos meios para ativar ainda mais as redes existentes e, assim, aumentar a colaboração entre estas. A meta final da pesquisa consiste, a partir dos conhecimentos produzidos, em aprimorar as condiçóes de trabalho dos dirigentes das creches, diante da abrangência de seu trabalho neste contexto de desenvolvimento, na perspectiva de potencializar a promoção do desenvolvimento das crianças, particularmente na primeira infância.

\section{Fundamentação Teórica}

A literatura nacional produziu e divulgou estudos, a partir de diferentes vertentes, que explicitaram os benefícios das creches para o desenvolvimento infantil, quando há investimento no cuidado com a saúde das crianças, com a formação do educador e com o envolvimento de pais e da comunidade (BRASIL, 1997; HADDAD, 1997; CAMPOS; ROSENBERG, 2009; FARIA; PALHARES, 2005; ROSSETTI-FERREIRA et al., 1998).

Ao lado destes estudos, estáo aqueles que pesquisam as políticas, a filosofia e a história das creches no
Brasil e da infância, na perspectiva sociológica (ROSENBERG, 1984; KUHLMANN JUNIOR, 1998; ABRAMOWICZ, 2011). O século passado dedicou-se, portanto, a produzir conhecimentos sobre os ganhos advindos do investimento na formação de educadores para impactar positivamente a criança no contexto da creche e o relevante papel das famílias e da comunidade no processo de educar e cuidar da criança. Náo resta dúvida sobre a importância da qualidade das interaçóes imediatas e não imediatas neste contexto de promoçáo do desenvolvimento, particularmente na primeira infância.

Neste cenário, a Educação Infantil passou a integrar a agenda nacional de educação. Dados do Observatório do Plano Nacional de Educação Brasileiro revelam, na atualidade, a necessidade de cumprimento de suas metas, particularmente a do desafio da expansão do atendimento de crianças em creche. Paralelamente a isto, é necessário que tal expansão aconteça acompanhada de qualidade, para reduzir desigualdades regionais presentes no cenário nacional (BRASIL, 2014a, 2014b).

Nos últimos anos, um grande número de programas de creches centra suas açóes na "formação dos professores da educação infantil”, para potencializar os impactos positivos na criança (HADDAD, 1997; CAMPOS; ROSENBERG, 2009). Acredita-se que, igualmente, essa mesma meta possa ser dirigida aos "dirigentes" (diretores/gestores) das creches, para aprimorar também suas condições de trabalho, considerando-se a abrangência de sua atuação e as competências que são exigidas a este profissional no cotidiano das creches.

Para liderar um conjunto de pessoas na creche e contribuir para a efetivação do programa (destacando-se, especialmente o cumprimento do projeto pedagógico), é esperado que os diretores atuem em conjunto com pessoas ou "instituiçôes" e que estejam disponíveis quando eles precisam (DELLA BARBA; MARTINEZ; CARRASCO, 2003; KRAMER, 2006; MARTINEZ et al., 2005). Acredita-se que a identificação das "forças e fraquezas" dos elementos que constituem a rede de apoio ou colaboração no cotidiano das creches pode levar à adoção de medidas para práticas mais seguras no dia a dia das creches. 
Esta pesquisa parte da hipótese de que as creches, para atingir a meta da promoção do desenvolvimento integral da criança e cumprir toda a proposta pedagógica, funcionam melhor se seus dirigentes podem contar com redes de apoio e colaboração entre serviços, com possibilidades de conexôes efetivas em situaçóes previsíveis e esperadas para o contexto da educaçáo infantil, efetivadas a partir de contratos entre os parceiros.

As creches públicas do Estado de São Paulo se configuraram como campo da presente pesquisa. O referencial teórico advindo do campo da psicologia está ancorado na perspectiva bioecológica do desenvolvimento humano de Urie Bronfenbrenner (1996), o qual deu a sustentação teórica inicial para a evolução desta investigação.

Nesta perspectiva, para esta pesquisa, foi proposto o conceito de "boas práticas em creche", que se refere às açóes de caráter interdisciplinar executadas nas creches, com vistas à garantia do pleno desenvolvimento infantil. As Boas Práticas em creches, constituídas como objeto do presente estudo, seriam aquelas examinadas no âmbito do exossistema ${ }^{1}$, uma vez que se busca conhecer um sistema de ligação entre contextos, neste caso, não imediatos à criança (BRONFENBRENNER, 1996, 2011).

\section{Objetivo}

O objetivo desta pesquisa foi identificar redes de colaboraçáo no contexto de creches públicas do Estado de Sáo Paulo.

\section{Método}

\subsection{Considerações éticas}

O projeto de pesquisa foi submetido ao Comitê de Ética em Pesquisa (CEP) da Universidade Federal de São Carlos e obteve o parecer favorável pelo n. ${ }^{\circ} 837.815 / 2014$, para respeitar e cumprir as prerrogativas da resolução da Comissão Nacional de Ética em Pesquisa (CONEP), que versa sobre ética em pesquisa em seres humanos.

Os participantes da pesquisa receberam e assinaram o Termo de Consentimento Livre e Esclarecido, com todas as informaçóes sobre o projeto, como: objetivo, procedimento da coleta de dados, resguardo da privacidade do participante e utilizaçáo dos dados para fins científicos.

\subsection{Definição do plano amostral}

O Estado de São Paulo conta com 645 municípios. Foi realizado o estudo das características dos municípios (dados populacionais) e optou-se por utilizar, como base para definição do plano amostral, o Índice Paulista de Responsabilidade Social (IPRS), por meio de seus indicadores: riqueza, longevidade e escolaridade (Tabela 1).

A seleçáo dos 32 municípios (5\% do Estado de Sáo Paulo), nesta pesquisa, considerou a princípio as 15 regiōes mapeadas pelo IPRS e a classificação destes de acordo com os Grupos de 1 a 5. Foram selecionadas 5\% de municípios de cada Grupo por meio de um sorteio. Entretanto, considerando-se a necessidade de se encontrarem creches nos referidos municípios e na perspectiva de encontrar também "boas práticas", foram priorizados aqueles que tinham $100 \%$ no quesito "escolaridade", de acordo com IPRS (ASSEMBLEIA..., 2012).

Diante do fato de haver vários municípios com $100 \%$ neste índice, os mesmos foram dispostos aleatoriamente nos dados do grupo ao qual faziam parte. Quando o município não aceitava participar, o próximo do mesmo grupo era selecionado.

Os dados da Tabela 2 apresentam o número de municípios por região.

\subsection{Participantes}

Participaram, desta pesquisa, 32 dirigentes de creches municipais do Estado de Sáo Paulo.

Tabela 1. Classificação IPRS dos municípios do Estado de São Paulo, versão 2012 (ASSEMBLEIA..., 2012).

\begin{tabular}{ll}
\multicolumn{1}{c}{ Grupos } & \multicolumn{1}{c}{ Classificação } \\
\hline Grupo 1 & $\begin{array}{l}\text { Municípios que se caracterizam por um nível elevado de riqueza com bons níveis } \\
\text { nos indicadores sociais } \\
\text { Municípios que, embora com níveis de riqueza elevados, não são capazes de atingir } \\
\text { brupo } 2\end{array}$ \\
Grupo indicadores sociais 3 & $\begin{array}{l}\text { Municípios com nível de riqueza baixo, mas com bons indicadores sociais } \\
\text { Municípios que apresentam baixos níveis de riqueza e níveis intermediários de } \\
\text { longevidade e/ou escolaridade }\end{array}$ \\
Grupo 5 & Municípios mais desfavorecidos, tanto em riqueza quanto nos indicadores sociais \\
\hline
\end{tabular}


Tabela 2. Representação da constituição do plano amostral.

\begin{tabular}{ccc}
\hline $\begin{array}{c}\text { REGIÃO/ } \\
\text { GRUPO }\end{array}$ & $\begin{array}{c}\text { NÚMERO DE } \\
\text { MUNICÍPIOS }\end{array}$ & $\begin{array}{c}\text { AMOSTRA } \\
\mathbf{( 5 \% )}\end{array}$ \\
\hline Grupo 1 & 78 & 4 \\
Grupo 2 & 75 & 4 \\
Grupo 3 & 191 & 9 \\
Grupo 4 & 202 & 9 \\
Grupo 5 & 98 & 6 \\
\hline
\end{tabular}

\subsection{Instrumento de coleta de dados}

Para atingir o objetivo da pesquisa, optou-se por utilizar a entrevista semiestruturada (LÜDKE; ANDRÉ, 1986). A entrevista foi composta por um roteiro contendo 20 questôes, cujo conteúdo baseou-se em situações problemas, presentes no dia a dia das creches. As situações abordaram temas presentes nas seguintes dimensôes: saúde, higiene, social, desenvolvimento, capacitação de educadores, infraestrutura e lazer.

Para cada dimensão, foram apresentadas três problemáticas, com exceção da "saúde" (seis problemáticas) e da "capacitação do educador", sendo esta abordada a partir de uma pergunta geral. Seguem exemplos das questóes em suas respectivas dimensões: Saúde (Se uma criança cair e se machucar na creche...); Higiene (Quando a creche identificar que a criança está com problemas de higiene, como falta de troca de fralda ou banho, roupa suja, assadura...); Social (Se uma criança chegar à creche com sinais no corpo de violência física ou sexual...); Desenvolvimento (Quando a creche identificar algum atraso no desenvolvimento da criança ou risco para deficiência...); Capacitação de educadores (Quem cuida da capacitação do educador da creche para que ele esteja atento ao cuidado integral da criança...); Infraestrutura e lazer (Se você perceber que a areia da creche está contaminada e há problemas com a caixa d'água da creche, como vazamento, sujeira, contaminação...). A última questão do roteiro foi dedicada ao desenho da rede, após a entrevista. Cada questão foi explorada a partir dos seguintes itens:

(1) Identificação da rede (citação e número de pontos);

(2) Formas de acionamento e periodicidade (acionamento regular e sistemático 'versus' acionamento conforme as necessidades);

(3) Meios de comunicação utilizados (documentais 'versus' contatos interpessoais);

(4) Grau de pactuação/formas de realização dos contratos (contratos formais 'versus' pactos informais).

\subsection{Procedimentos de coleta e análise dos dados}

Os dados foram coletados por meio de entrevistas semiestruturadas, as quais foram gravadas e, posteriormente, analisadas. Em síntese, os dados foram analisados de forma qualitativa, referente ao conteúdo, e de forma quantitativa, pertinente à mensuraçáo dos dados coletados em planilhas. Cabe ressaltar que, para o presente artigo, serão apresentados e analisados apenas os dados referentes à identificaçáo dos pontos das redes citado no item (1).

\section{Resultados e Discussão}

Os resultados trazem informaçóes sobre a morfologia das redes no que se refere à sua extensão. Foi identificado, a partir das respostas dos dirigentes, um rol de 75 pontos $^{2}$ de contato nas redes das 32 creches que compuseram a amostra desta pesquisa.

Os pontos de contato referem-se a equipamentos, profissionais, programas e família, os quais foram organizados a partir de duas categorias profissionais/ instituições (programas e órgãos governamentais) elencadas e agrupadas conforme consta na Tabela 3, a seguir.

Além dos resultados gerais, os dados sobre os pontos das redes foram analisados a partir das dimensôes (higiene, saúde, desenvolvimento, social, infraestrutura e lazer e capacitação de educadores), conforme abrangidas pelas questóes presentes no roteiro de entrevistas (Tabela 4).

$\mathrm{O}$ agrupamento das questôes possibilitou identificar os pontos presentes nas redes, a partir das dimensóes estabelecidas (Tabela 5).

Assim, observou-se que as dimensóes "desenvolvimento e saúde" são superiores às demais. Nestas dimensốes, encontram-se os equipamentos advindos das redes de saúde e de educação. Tais equipamentos de saúde e educação estấo voltados para a promoção do desenvolvimento infantil e contemplam os diferentes níveis de atençáo.

No que se refere ao campo da saúde, sua estruturaçáo em níveis de assistência é clara e amplamente divulgada. No Brasil, o Governo Federal, para oferecer uma atenção em saúde organizada, ofertou, pelo Sistema Único de Saúde (CECCIM; FEUERWERKER, 2004), açóes a partir de níveis (Primário, Secundário e Terciário, com alguns hospitais localizados em Quaternário) de assistência.

Desta forma, após investimento na divulgação de tal organizaçáo e, acima de tudo, a partir da vivência da população, os gestores entrevistados 


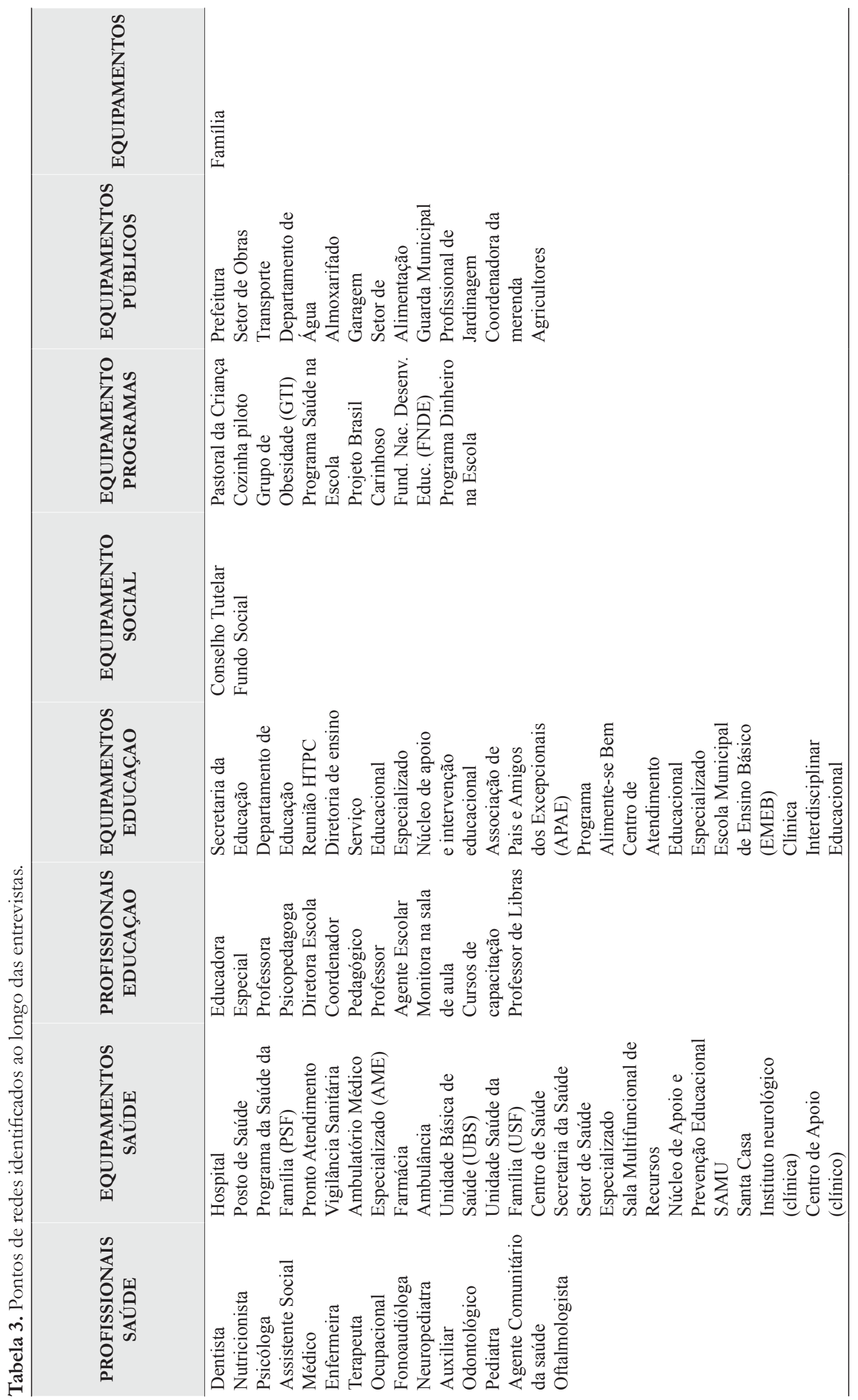


Tabela 4. Dimensões estabelecidas por meio das redes.

\begin{tabular}{cc}
\hline Fator1 & Variável Dependente \\
\hline 1 & HigRedeT_1 \\
2 & SauRedeT_1 \\
3 & DesRedeT_1 \\
4 & SocRedeT_1 \\
5 & InLaRedeT_1 \\
6 & CapRedeT_1 \\
\hline
\end{tabular}

Tabela 5. Pontos de redes comparados por dimensões.

\begin{tabular}{ccccccccc}
\hline Dimensão & Hig & Saúde & Desenv & Social & Infra_La & Capac & F & Sig \\
\hline REDE & $4,50^{\mathrm{a}}$ & $5,31^{\mathrm{b}}$ & $5,87^{\mathrm{b}}$ & $4,15^{\mathrm{a}}$ & $4,26^{\mathrm{a}}$ & $3,82^{\mathrm{a}}$ & 14,22 & $<, 001$ \\
& $(1,15)$ & $(1,09)$ & $(1,75)$ & $(0,86)$ & $(0,76)$ & $(1,55)$ & & \\
\hline
\end{tabular}

${ }^{\mathrm{a}} \mathrm{e}^{\mathrm{b}}$ são duas grandes categorias de agrupamento que mostram similaridades e discrepâncias entre as dimensões. Como pode ser observado há um grupo com valores menores, denominado a $4.50 ; 4,15 ; 4,26 ; 3.82$ e outro grupo com valores maiores, denominado ${ }^{\text {b }} 5.31 ; 5.87$.

revelaram conhecimento acerca da organização dos serviços de saúde pública brasileiros, citando o uso dos equipamentos frente às demandas do cotidiano das creches.

Para Mendes (2011), as redes de atenção à saúde são organizações de conjuntos de serviços de saúde unidos por uma missão única, para uma ação cooperativa que possibilita a "atenção contínua e integral a determinada população". O autor acredita que, embora ainda no Brasil não haja avaliações "robustas", as redes de atenção à saúde podem ter impacto significativo nos níveis de saúde.

Acredita-se que o conhecimento, por parte dos dirigentes das creches, sobre a organização da atenção à saúde frente aos graus de complexidade pode, sem dúvida, ser um elemento importante para favorecer a intersetorialidade no âmbito das açôes em creches. Os dirigentes das creches reúnem papéis e funçóes para os quais são fundamentais as habilidades sociais e os conhecimentos específicos.

Em relação aos equipamentos e profissionais das redes presentes na dimensáo "desenvolvimento", estes foram constituídos por apoios advindos tanto pelo campo da saúde quanto pelo campo da educação. Nesta, incluem-se as escolas especiais, os apoios educacionais, as salas de atendimento educacional, as diretorias, entre outros, para a resolução dos problemas relacionados ao desenvolvimento.

Numa perspectiva de desenvolvimento integral da criança, observa-se a pertinência de contar com ambos os campos de atuaçáo frente aos riscos ao desenvolvimento e também às possibilidades de proteção à criança. $\mathrm{O}$ dirigente beneficia a instituição (creche), famílias e criança, quando tem uma clareza de seu papel na promoçáo do desenvolvimento infantil, particularmente na primeira infância.
O papel dos adultos frente às possibilidades de proteção à criança é destacado por Maia e Williams (2005, p. 91):

Em 1990, entra em vigor, no Brasil, o Estatuto da Criança e do Adolescente (ECA, Lei Federal n. 8069, 1990), responsável por muitas mudanças no cenário brasileiro, em relação à visão dos direitos das crianças e dos adolescentes, sendo esse um instrumento importante para a proteção de crianças e jovens. Cabe destacar a obrigatoriedade estabelecida pelo ECA em seu artigo 245 de que todo profissional das áreas social, educação ou saúde, deva comunicar à autoridade competente os casos de seu conhecimento envolvendo suspeita ou confirmação de maus-tratos contra a criança ou adolescente, cabendo pena prevista caso tal comunicação não ocorra... É necessário, porém, que todos os profissionais que atuem na área da infância e da adolescência tenham conhecimento dos direitos estabelecidos pelo ECA (1990), bem como dos fatores de risco envolvidos no prejuízo ao desenvolvimento infantil, para que possam intervir de forma precisa na prevenção e/ou interrupçáo do risco.

Em complementaridade aos dados das dimensóes Saúde e Desenvolvimento, destacou-se a "capacitação de educadores". Em 2006, Kramer, ao discutir o tema da educação infantil no contexto político nacional, aborda relativamente à formaçáo do profissional de educação infantil, apontando-a como um desafio. Entretanto, na presente pesquisa, a capacitação do educador surge como uma dimensão potente nas redes ainda que, na prática, ressente-se da ausência de uma política nacional agressiva de formação dos profissionais da educação infantil. 
Sintetizando, o presente estudo evidenciou a forte presença da intersetorialidade advinda dos campos da educação, da saúde e do social. Corroborando com estes achados, Della Barba, Martinez e Carrasco (2003) afirmaram que uma visão intersetorial pode se constituir em um caminho, quando se objetiva a promoção da saúde e da educaçáo de crianças pequenas no Brasil. Dessa forma, saúde, ambiente e desenvolvimento são conceitos que não podem caminhar sozinhos.

A extensão de cada rede depende, certamente, das condiçôes de cada município e ainda das habilidades de constituição, acionamento e manutenção das redes pelos dirigentes, suas competências e conhecimentos.

Em relação às habilidades dos dirigentes, acredita-se que o locus privilegiado do diretor, no contexto do estabelecimento de um número considerável de interaçôes, pode produzir e manter relaçôes saudáveis no contexto das creches, gerando consequências positivas para todo o contexto. Para Caballo (2006), muitos problemas humanos podem ser decorrência de um déficit de habilidades sociais. Essas formam um elo entre o indivíduo e as pessoas que o cercam. Se este elo está enfraquecido ou é disfuncional, podem não ser geradas consequências reforçadoras o suficiente para que o indivíduo tenha o que se chama de "vida satisfatória" ou "vida feliz".

Esse autor considera que o comportamento socialmente hábil é aquele conjunto de comportamentos emitidos por um indivíduo em um contexto interpessoal específico, expressando sentimentos, atitudes, desejos, opinióes ou direitos, de modo adequado àquela situação; respeitando os demais e, geralmente, resolvendo os problemas imediatos da situação ao mesmo tempo em que minimiza a probabilidade de problemas futuros (CABALLO, 2006). Assim, para a efetivação das políticas públicas de educação, sugerem-se investimentos na formação dos dirigentes das creches frente ao seu papel estratégico no processo de promoçấo do desenvolvimento integral da criança.

\section{Conclusão}

Esta pesquisa trouxe uma contribuição importante, ao privilegiar um contexto pouco explorado: a identificação de redes de colaboração no contexto de creches públicas do Estado de São Paulo. Partiu-se da hipótese de que as creches, para cumprir suas metas, funcionam melhor quando seus dirigentes contam com interaçóes no cotidiano entre pessoas e instituiçóes (redes) com possibilidades de conexóes efetivas, em situaçóes previsíveis e esperadas para o contexto da educaçáo infantil. Neste contexto, o presente estudo produziu resultados positivos, evidenciando que um conjunto de açóes, em rede, coordenadas pelos gestores das creches, pode impactar positivamente o desenvolvimento integral da criança.

Os achados revelaram que, para além do que tradicionalmente a literatura tem apontado como redes de colaboração em creches, os equipamentos municipais se constituem em apoios de infraestrutura aos gestores, sendo uma nova dimensão identificada. Ao seu lado, surge também a forte presença de diversos programas governamentais oriundos $\mathrm{da}$ esfera federal. Para futuros estudos, aponta-se para a possibilidade de validar tais pontos numa rede junto a um número maior de participantes e municípios.

A dimensão do desenvolvimento infantil está presente de forma intensa na esfera da educação e da saúde, havendo, entretanto, diferenças entre tais dimensóes com as advindas do campo social. Acredita-se que a identificação das dimensóes e dos pontos das redes possa contribuir para reflexôes sobre o atendimento à criança na perspectiva da integralidade de seu cuidado no contexto das creches.

\section{Referências}

ABRAMOWICZ, A. A pesquisa com crianças em infâncias e a sociologia da infância. In: FARIA, A. L. G.; FINCO, D. (Org.). Sociologia da infância no Brasil. Campinas: Autores Associados, 2011. p. 17-31.

ASSEMBLEIA LEGISLATIVA DO ESTADO DE SÃO PAULO - ALESP. Instituto do Legislativo Paulista ILP. IPRS - Índice Paulista de Responsabilidade Social. Sáo Paulo, 2012. Disponível em: <http://indices-ilp. al.sp.gov.br/view/index.php?prodCod=1>. Acesso em: 10 jul. 2015.

BRASIL. Ministério da Educaçáo e do Desporto. Secretaria da Educação Fundamental. Referenciais Curriculares Nacionais para a Educação Infantil. Brasília, 1997.

BRASIL. Plano Nacional de Educação 2014-2024. Brasília: Câmara dos Deputados, Ediçôes Câmara, 2014a. Disponível em: <http://www.observatoriodopne.org.br/ uploads/reference/file/439/documento-referencia.pdf>. Acesso em: 10 jul. 2015.

BRASIL. Lei no 13.005 , de 25 de junho de 2014. Aprova o Plano Nacional de Educação (PNE) e dá outras providências. Diário Oficial [da] República Federativa do Brasil, Brasília, DF, 26 jun. 2014b. Disponível em: <http:// www.planalto.gov.br/ccivil_03/_Ato2011-2014/2014/ Lei/L13005.htm>. Acesso em: 10 jul. 2015.

BRONFENBRENNER, U. A ecologia do desenvolvimento humano: experimentos naturais e planejados. Porto Alegre: Artes Médicas, 1996. 
BRONFENBRENNER, U. Bioecologia do desenvolvimento humano: tornando os seres humanos mais humanos. Porto Alegre: Artmed, 2011.

CABALLO, V. E. Manual de avaliação e treinamento das habilidades sociais. São Paulo: Santos, 2006.

CAMPOS, M. M.; ROSEMBERG, F. Critérios pra um atendimento em creches que respeite os direitos fundamentais das crianças. Brasília: MEC, SEB, 2009.

CECCIM, R. B.; FEUERWERKER, L. C. M. O Quadrilátero da formação para a área da saúde: Ensino, Gestão, Atenção e Controle Social. Revista de Saúde Coletiva, Rio de Janeiro, v. 14, n. 1, p. 41- 65, 2004.

DELLA BARBA, P. C.; MARTINEZ, C. M. S.; CARRASCO, B. Promoção da saúde e educação infantil: caminhos para o desenvolvimento. Paidéia, Ribeirão Preto, v. 13, n. 26, p. 141-146, 2003.

FARIA, A. L. G.; PALHARES, M. S. Educação infantil Pós- $L D B$ : rumos e desafios. Campinas: Autores Associados - FE/UNICAMP; São Carlos: Editora da UFSCar; Florianópolis: Editora da UFSC, 2005.

HADDAD, L. A ecologia do atendimento infantil: construindo um modelo de sistema unificado de cuidado e educação. 1997. 327 f. Tese (Doutorado em Educação) - Universidade de São Paulo, São Paulo, 1997.

KRAMER, S. As crianças de 0 a 6 anos nas políticas educacionais no Brasil: educação infantil e/é fundamental. Educação \& Sociedade, Campinas, v. 27, n. 96, p. 797-818, 2006.
KUHLMANN JUNIOR, M. Infância e educação infantil: uma abordagem histórica. Porto Alegre: Editora Mediação, 1998.

LÜDKE, M.; ANDRÉ, M. Pesquisa em educação: abordagens qualitativas. São Paulo: EPU, 1986.

MAIA, J. M.; WILLIAMS, L. C. A. Fatores de risco e fatores de proteção ao desenvolvimento infantil: uma revisão da área. Temas em Psicologia, Ribeirão Preto, v. 13, n. 2, p. 91-103, 2005. Disponível em: < http://www.laprev.ufscar.br/documentos/arquivos/artigos/2005-maia-e-williams.pdf>. Acesso em: 10 jul. 2015.

MARTINEZ, C. M. S. et al. Desenvolvimento de bebês: atividades cotidianas e a interação com o educador. São Carlos: EDUFSCar, 2005.

MARTINHO, C. Algumas palavras sobre rede. In: SILVEIRA, C. M. S.; REIS, L. C. (Org.). Desenvolvimento local: dinâmicas e estratégias. Rio de Janeiro: Rede DLIS, 2001. p. 1-7.

MARTINHO, C. Redes: uma introdução às dinâmicas da conectividade e da auto-organização. Brasília: WWF, 2003.

MENDES, E. V. As redes de atenção à saúde. Brasília: Organização Pan-Americana da Saúde, 2011.

ROSENBERG, F. O movimento de mulheres e a abertura política no Brasil: o caso das creches. Cadernos de Pesquisa, São Paulo, v. 51, p. 73-79, 1984.

ROSSETTI-FERREIRA, M. C. et al. Os fazeres na educação infantil. São Paulo: Cortez, 1998.

\section{Contribuição dos Autores}

Claudia foi responsável pela orientação do projeto e redação do texto. Anne Marie e Jair contribuíram por meio de parcerias, consultorias e elaboraçâo do texto. Bruna foi bolsista de treinamento técnico da Fapesp e contribuiu na coleta dos dados. Mariana foi responsável por parte da redação, organização do texto e das referências. Todos os autores aprovaram a versão final do texto.

\section{Fonte de Financiamento}

FAPESP e Fundação Maria Cecília Vidigal - (No do processo FAPESP - 2014/ 07997-3).

\section{Notas}

${ }^{1}$ A Teoria Bioecológica de Urie Bronfenbrenner (2011) defende que o desenvolvimento humano se dá por meio da interação sinérgica entre quatro núcleos: pessoa, processo, tempo e contexto. O núcleo contexto representa os ambientes que oferecem influência sobre o desenvolvimento dos indivíduos, sendo subdividido em Microssistema, Mesossistema, Exossistema e Macrossistema. À luz desta teoria, Exossistema refere-se a um ou mais ambientes que não necessariamente envolvem o indivíduo como um participante ativo, mas no qual ocorrem processos que afetam ou são afetados por aquilo que acontece nos ambientes imediatos ao indivíduo, com implicaçóes sobre seu desenvolvimento.

${ }^{2}$ A rede apresenta, em seu aspecto formal, um conjunto de pontos interligados a outros pontos por meio de linhas. Estes pontos podem representar as unidades que compóem a rede, como as pessoas, as organizaçóes, os equipamentos, os locais, entre outras. As linhas podem representar as relaçôes existentes entre estes elementos, como os canais de comunicação, as estradas, os dutos, os fios, entre outros (MARTINHO, 2001, 2003). 